\title{
FIBROUS DYSPLASIA OF SPHENOID BONE IN A 4-YEAR-OLD WITH UNILATERAL PROPTOSIS
}

\author{
Fahad Faiz'1, Nameer Faiz², Abhishek Agrawal ${ }^{3}$
}

${ }^{1}$ Clinical Fellow, Cataract-IOL and Anterior Segment Services, Aravind Eye Hospital, Madurai.

${ }^{2}$ Senior Resident, Department of General Surgery, Indira Gandhi Institute of Medical Sciences, Patna. ${ }^{3}$ Clinical Fellow, Cataract-IOL and Anterior Segment Services, Aravind Eye Hospital, Madurai.

HOW TO CITE THIS ARTICLE: Faiz F, Faiz N, Agrawal A. Fibrous dysplasia of sphenoid bone in a 4-year-old with unilateral proptosis. J. Evolution Med. Dent. Sci. 2017;6(47):3668-3670, DOI: 10.14260/Jemds/2017/791

\section{PRESENTATION OF CASE}

A 4-year-old male child presented to the Eye OPD with complaints of protrusion of left eye since 2 months (Fig. 1). The protrusion was gradually progressive and the patient also complained of associated headache. There was no h/o fever, trauma, pain or redness around the orbital swelling or diplopia.

At the time of presentation, best corrected visual acuity recorded was 6/6 in $\mathrm{RE}$ and $\mathrm{FC}$ at $3 \mathrm{~m}$ in LE (Snellen test types). There was eccentric proptosis of the LE with displacement of the eyeball inferotemporally. Slit-lamp examination showed normal anterior segment in both eyes. On diffuse light examination pupil was normal in size, briskly reactive to light in RE, LE showed Relative Afferent Pupillary Defect (Grade I). On fundoscopy, LE optic disc showed slight disc pallor. Extraocular movements in the affected eye were restricted medially and were normal in the other eye. The case was referred to Neurosurgery for their opinion on further management and was being prepared for surgery. On followup visit after 20 days the vision in left eye was deteriorated to PL+, LE pupil showed RAPD Grade III and there was primary optic atrophy in LE. No evidence of raised intracranial tension or leukocoria. No ocular or dermatological finding related to neurofibromatosis was found. General examination revealed no other bony lesions or abnormality elsewhere in the body.

Routine blood investigations were within normal limits. A contrast-enhanced CT-scan brain and orbit (Fig. 2) was advised which showed a well-defined, hyperdense, strongly enhancing, broad-based extra-axial lesion in left frontotemporal region with retroconal extension into left orbit causing displacement of optic nerve. Also, extensive erosion and destruction of adjacent greater wing of sphenoid bone was noted. A provisional diagnosis of Meningioma was made. In order to confirm the diagnosis, an MRI (with and without contrast) was undertaken. The MRI (Fig. 3 and Fig. 4) revealed a large $(5.5 \mathrm{~cm} \times 3.5 \mathrm{~cm} \times 3 \mathrm{~cm})$ lesion, which was isointense on $\mathrm{T} 1$ and $\mathrm{T} 2$-weighted images involving left sphenoid bone with involvement of left orbit causing compression of Optic Nerve and showing peripheral enhancement, which was suggestive of fibrous dysplasia of left sphenoid bone. The patient was referred to Department of Neurosurgery, where an immediate surgery was

Financial or Other, Competing Interest: None.

Submission 06-05-2017, Peer Review 01-06-2017,

Acceptance 06-06-2017, Published 12-06-2017.

Corresponding Author:

Dr. Nameer Faiz,

Flat 101, Emarat Farhat Apartment,

Chitkora, Road-24, Gardanibagh,

Patna-800002, Bihar.

E-mail:drnameerfaiz@gmail.com

DOI: $10.14260 /$ jemds $/ 2017 / 791$ undertaken for Optic Nerve decompression. A 4-month followup was done. Patient's visual acuity of Left Eye improved to Finger Count (Close to face) with mild reduction in proptosis and relief of headache.

\section{PATHOLOGICAL DISCUSSION}

In 1937, McCune and Bruch first suggested that of all the abnormalities of bone formation, this disorder should have its own place as a distinct clinical entity.[1] The following year, Lichtenstein introduced the term fibrous dysplasia.[1]

The disease is of particular interest to the ophthalmologist, because it can affect the craniofacial bones. When the craniofacial bones are affected, encroachment on the paranasal sinuses, orbit and foramina of the skull can produce visual loss, proptosis, diplopia and epiphora.

Three categories of this disease have been describedMonostotic Fibrous Dysplasia (MFD) involves a single bone and represents $70 \%$ of all cases; commonly involves femur, tibia or facial bones. It generally becomes arrested by puberty. There is an equal male-to-female ratio. Polyostotic Fibrous Dysplasia (PFD) involves multiple bones, most frequently of the lower limbs. In the skull, sphenoid and frontal bones are affected. These lesions may be localised to one region of the body or they may be disseminated, involving virtually every bone. There is a female predilection in polyostotic fibrous dysplasia. These lesions are more likely to continue to progress even after puberty, beyond the third or fourth decades. McCune-Albright Syndrome (MAS) is seen in approximately $3 \%-5 \%$ of patients with fibrous dysplasia. In this the bony involvement is associated with sexual precocity, hyperthyroidism and café-au-lait macular spots. It primarily affects females. A possible relationship between fibrous dysplasia and primary hyperparathyroidism has been suggested. $[1,2]$

Fibrous dysplasia involving the face and skull is called "Leontiasis ossea." Without treatment, one or more bones progressively increase in size and move into the cavities of the eye, mouth and/or the nose and its sinuses. Also, abnormal protrusion of the eyeball (Exophthalmos) may develop and eventually cause complete loss of sight, because it presses on the optic nerve.[3]

Among patients with skull lesions, the frontal bones are most commonly involved followed by the sphenoid, ethmoid, parietal, temporal and occipital bones. Advanced imaging methodologies demonstrated that ethmoid involvement is the most common, followed by the sphenoid and frontal bones. $[4,5]$

Isolated lesion of sphenoid bone is a rare entity, ${ }^{[6]}$ as polyostotic lesions involve multiple bones. In this case also there is isolated involvement of left sphenoid bone which was extending into left orbit; rest of facial bones were normal. 
Lustig et al in their study of 21 cases of fibrous dysplasia of facial bones had found involvement of sphenoid in $43 \%$ patients. But in all these cases there was multiple bone involvement, not even a single case of isolated lesion of sphenoid was found.[5]

Faraci RP and Ketcham AS reported a case of isolated sphenoid lesion in 13-year-old black male. They reported that one year following admission, the patient's proptosis disappeared and his symptoms were markedly improved.[7]

The clinical picture of skull base FD depends on the pathologic bone's compressive effect against adjacent structures. Patients are usually asymptomatic and present with a painless bony enlargement leading to deformity and asymmetry. ${ }^{[8,9]}$ The most common symptoms are facial asymmetry, bone mass, blurred vision, headache, epiphora, eyelid position abnormalities, loss of visual field, diplopia, sinusitis, epistaxis and hearing loss.[10]

Computed tomography is the investigation of choice for diagnosis and followup, because of its superior bony details and accurate assessment of the extent of the lesion. CT is efficient for assessing cranial nerve entrapment and optic nerve compression.[11,12] Three-dimensional bone reconstruction with helical CT gives optimal visualisation of the extent of dysplastic bone in the skull base.[13] FD has characteristic appearances on CT: a ground-glass pattern (50\%), a homogeneously dense pattern (25\%) and cystic variety (20\%).[14]

MRI is an additional useful modality that can help distinguish fibrous dysplasia from meningioma, osteoma or mucocele and define the extent of soft tissue involvement, particularly if central nervous system structures are impinged on.

On MRI, the signal intensity on T1- and T2-weighted images depends on several factors including the amount of bone trabeculation and the degree of cellularity. ${ }^{[15,16]}$ Characteristically, lesions show low signal intensity and welldemarcated borders on both T1- and T2-weighted images.

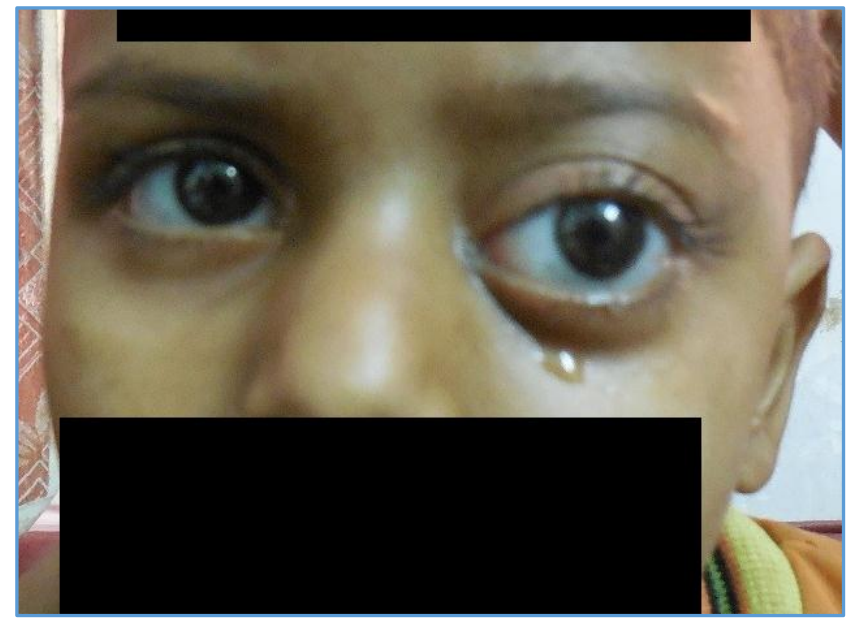

Figure 1. Eccentric Proptosis of the LE with Displacement of the Eyeball Inferotemporally

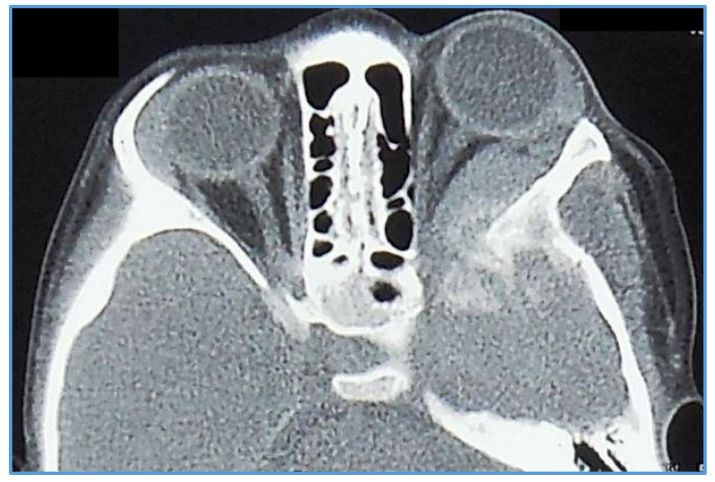

Figure 2. CECT of Brain and Orbit

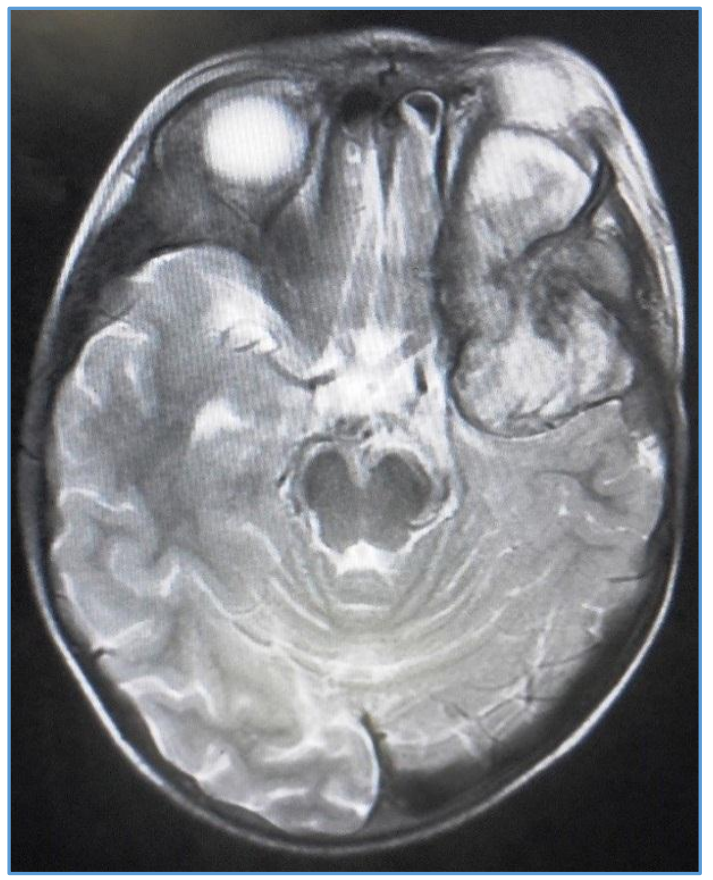

Figure 3. MRI without Contrast

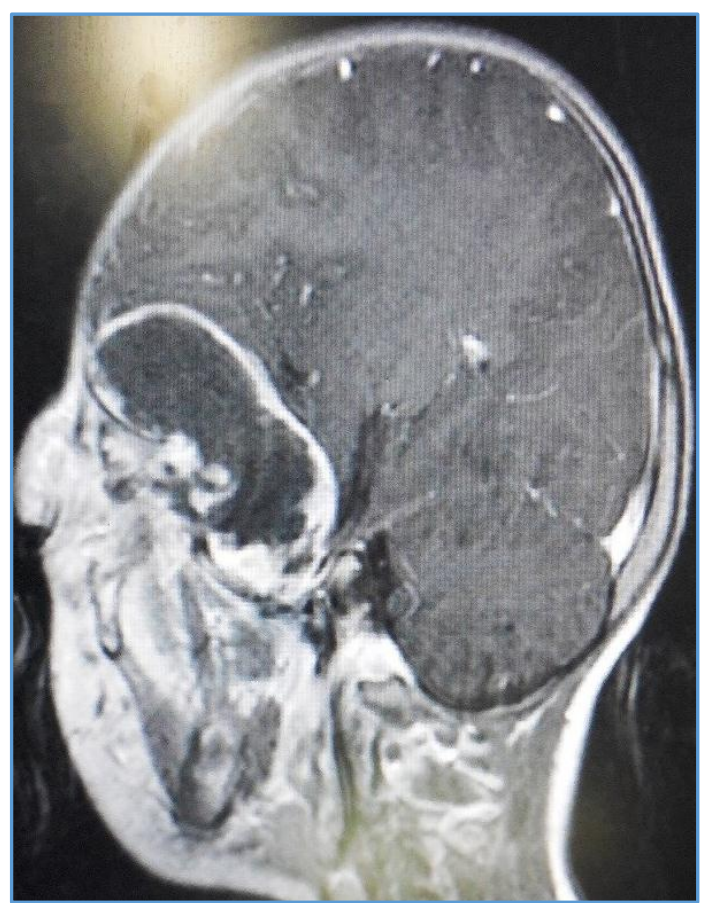

Figure 4. MRI with Contrast Enhancement 


\section{DISCUSSION OF MANAGEMENT}

Management should focus on three directives: The restoration of function, the prevention of complications and the restitution of cosmesis.

It is generally acceptable that asymptomatic sphenoid FD does not necessitate biopsy or surgery, and that a clinicoradiological followup is sufficient. Surgery is advocated once patients become symptomatic (e.g. cranial neuropathies, pain or disfigurement).

A major issue in the management of patients with CFD is the role of optic canal decompression. In FD of the sphenoid bone, the rate of Optic Nerve involvement is 50\% to $90 \%$.[17] The degree of ON involvement varies between mild impingement of the nerve to a totally encased nerve. Decompression is not risk free, and cases of blindness and visual deterioration in asymptomatic patients have been reported.[18] Following on decompression in our patient, visual acuity improved to Finger Count because of timely intervention before total visual loss. Studies have demonstrated that vision is less likely to return if the decompression is done more than one week after established blindness.[19] Decompression has been shown to have no value in cases of blindness of more than one month duration. [20]

\section{FINAL DIAGNOSIS}

Monostotic Fibrous Dysplasia of sphenoid bone, Isolated Fibrous Dysplasia of sphenoid bone is a rare entity. It is a benign disease that has the potential to cause significant cosmetic and functional disturbance, especially visual impairment. Such cases usually present to the ophthalmologist first. With proper understanding, diagnosis and management, the outcome can be improved.

\section{REFERENCES}

[1] Albright F, Butler M, Hampton AO, et al. Syndrome characterized by osteitis fibrosa disseminata, areas of pigmentation and endocrine dysfunction with precocious puberty in females. $\mathrm{N}$ Engl J Med 1937;216:727-46.

[2] McCune D, Bruch H. Osteodystrophia fibrosa. Report of a case in which the condition was combined with precocious puberty, multiple pigmentation of the skin and hyperthyroidism. Am J Dis Child 1937;52:745.

[3] El Deeb M, Waite DE, Gorlin RJ. Congenital monostotic fibrous dysplasia-a new possibly autosomal recessive disorder. J Oral Surg 1979;37(7):520-5.

[4] Abdelkarim A, Green R, Startzell J, et al. Craniofacial polyostotic fibrous dysplasia: a case report and review of the literature. Oral Surg Oral Med Oral Pathol Oral Radiol Endod 2008;106(1):e49-55.

[5] Lustig LR, Holliday MJ, McCarthy EF, et al. Fibrous dysplasia involving the skull base and temporal bone. Arch Otolaryngol Head Neck Surg 2001; 127(10):1239-47.
[6] Sethi DS. Isolated sphenoid lesions: diagnosis and management. Otolaryngol Head Neck Surg 1999;120(5):730-6.

[7] Faraci RP, Ketcham AS. Fibrous dysplasia of the sphenoid sinus in an adolescent male. J Surg Oncol 1975;7(6):461-5.

[8] Becelli R, Perugini M, Cerulli G, et al. Surgical treatment of fibrous dysplasia of the cranio-maxillofacial area. Review of the literature and personal experience form 1984 to 1999. Minerva Stomatol 2002;51(7-8):293-300.

[9] Yavuzer R, Bone H, Jackson IT. Fronto-orbital fibrous dysplasia. Orbit 2000;19(2):119-28.

[10] Rahman AM, Madge SN, Billing K, et al. Craniofacial fibrous dysplasia: clinical characteristics and longterm outcomes. Eye (Lond) 2009;23(12):2175-81.

[11] Chen YR, Wong FH, Hsueh C, et al. Computed tomography characteristics of non-syndromic craniofacial fibrous dysplasia. Chang Gung Med J 2002;25(1):1-8.

[12] Tehranzadeh J, Fung Y, Donohue M, et al. Computed tomography of paget disease of the skull versus fibrous dysplasia. Skeletal Radiol 1998;27(12):66472.

[13] MacDonald-Jankowski DS. Fibro-osseous lesions of the face and jaws. Clin Radiol 2004;59(1):11-25.

[14] Brown EW, Megerian CA, McKenna MJ, et al. Fibrous dysplasia of the temporal bone: imaging findings. AJR Am J Roentgenol 1995;164(3):679-82.

[15] Jee WH, Choi KH, Choe BY, et al. Fibrous dysplasia: MR imaging characteristics with radiopathologic correlation. AJR Am J Roentgenol 1996;167(6): 1523-7.

[16] Yano M, Tajima S, Tanaka Y, et al. Magnetic resonance imaging findings of craniofacial fibrous dysplasia. Ann Plast Surg 1993;30(4):371-4.

[17] Chen YR, Breidahl A, Chang CN. Optic nerve decompression in fibrous dysplasia: indications, efficacy, and safety. Plast Reconstr Surg 1997;99(1):22-30.

[18] Michael CB, Lee AG, Patrinely JR, et al. Visual loss associated with fibrous dysplasia of the anterior skull base. Case report and review of the literature. J Neurosurg 2000;92(2):350-4.

[19] Gass JD. Orbital and ocular involvement in fibrous dysplasia. South Med J 1965;58:324-9.

[20] Papay FA, Morales L, Flaharty P, et al. Optic nerve decompression in cranial base fibrous dysplasia. J Craniofac Surg 1995;6(1):5-10. 